\title{
Article
}

\section{Blockchain Technology Adoption in Supply Chain Finance}

\author{
Arief Rijanto $(\mathbb{D}$
}

check for

updates

Citation: Rijanto, A. Blockchain Technology Adoption in Supply Chain Finance. J. Theor. Appl. Electron. Commer. Res. 2021, 16, 3078-3098. https://doi.org/10.3390/jtaer16070168

Academic Editor: Jani Merikivi

Received: 12 August 2021

Accepted: 26 October 2021

Published: 8 November 2021

Publisher's Note: MDPI stays neutral with regard to jurisdictional claims in published maps and institutional affiliations.

Copyright: (C) 2021 by the author. Licensee MDPI, Basel, Switzerland. This article is an open access article distributed under the terms and conditions of the Creative Commons Attribution (CC BY) license (https:/ / creativecommons.org/licenses/by/ $4.0 /)$.
School of Business and Economics, Universitas Prasetiya Mulya, DKI Jakarta 12430, Indonesia; arief.rijanto@prasetiyamulya.ac.id

\begin{abstract}
Supply Chain Finance (SCF) faces the complex problem of implementing inventory, purchase order and accounts receivable financing automation in terms of transaction data trust and validation. This paper aims to explore how blockchain technology adoption solves the SCF problem using a multi-case method based on the Technological Acceptance Model (TAM). With purposive sampling, 30 cases were selected on the criteria of perceived usefulness and perceived ease of use in solving SCF problems. The results show that trust, validity and distributed ledger transaction data as perceived usefulness are the main drivers of blockchain adoption because it provides solutions to SCF automation problems such as Know Your Customer (KYC), accounting, and transaction settlement. Smart contracts offer easy and fast transactions such as in L/C export processing as perceived ease to use. Of the 30 blockchain projects, 21 offer the usefulness of automated accounts receivable financing, 15 offer easy-to-use purchase order financing and 8 offer easy-to-use inventory financing processes. This study provides the current state of blockchain technology adoption by exploring 30 real application cases in SCF globally. Blockchain advantages provide automation solutions in global supply SCF practices with smart contracts, transparency and security of distributed ledger data feature.
\end{abstract}

Keywords: supply chain finance; blockchain; TAM

\section{Introduction}

The role of Supply Chain Finance (SCF) is increasingly being considered as an advantage for business processes. Supply chain financing is a financial management solution that benefits both suppliers and buyers to increase working capital. Buyers use trade credit as cash flow management to maintain business financial liquidity. From the supplier's point of view, trade credit allows suppliers to set favorable payment dates without disrupting their cash flow [1]. Buyers can take advantage of the extended payment due date, and suppliers get cash faster to maintain positive working capital because of advance payment. Financing supply chain finance activities can also come from financial institutions. Suppliers get immediate cash and buyers get extended payment terms. The main function of supply chain finance is to help provide financial liquidity and working capital to suppliers so they can run business efficiently where buyers continue to benefit from backwards payments [2-4].

SCF main goals is to optimize financial flows between various levels of business processes through solutions offered by financial institutions, technology providers and other related parties. Therefore, SCF has the characteristics that the relationship between supply chain players and financial institutions greatly influences the successful implementation of cash flow management efficiency solutions. For example, SCF as a factoring reversal case in which the buying company facilitates the early payment of trade credit obligations to the supplier. This occurs based on an assessment of the buyer-supplier relationship with financial institutions as risk bearers and assessors of the buyer's creditworthiness [5-9].

The length of the supply chain transaction process is also slowed by weak contracts, taxes, legal and institutional administration so that interactions between the parties and standard procedures between supply chain partners are ineffective and inefficient. Then, 
inconsistent and different governance structures in each company can make it difficult to collect information so that credit decisions are limited and access to historical data to evaluate credit risk is more difficult. Buyers cannot monitor receivables from products purchased. Often the seller can still go through the process of monitoring receivables because it cannot be observed by the buyer. As a result, the problem of transparency and fraud is a major problem in conventional reverse factoring practices $[2,6,10]$.

Data transparency, validity, speed, and security related to the activities carried out by sellers and buyers are still the main obstacles. The implementation of technology to solve this problem has the potential to increase the company's operational costs so that it can lead to the perception that the benefits of SCF are not so attractive in reducing working capital costs. There needs to be a breakthrough in technological innovation related to this SCF problem. Blockchain technology has great potential in making breakthrough solutions to problems in SCF because available technology is relatively inexpensive.

The concept of distributed ledgers from blockchain technology has unique innovations and capabilities in ensuring transparency, validity, security, traceability, efficiency, speed and automatic data verification. However, even though the potential benefits of blockchain technology are quite large in SCF adoption of blockchain technology raises the question, is this technology really able to save costs for the parties involved compared to using traditional SCF technology, such as paper-based invoicing? There are also potential costs associated with adopting a blockchain platform as a new technology even though there are potential cost savings from using blockchain related to new technology adoption activities such as the cost of expertise during implementation [10].

Blockchain technology is very suitable for environments that require high verification and validation, but can still adapt to environmental changes and government regulations such as regulatory bodies. Blockchain technology system to support vaccine tracking and smart contracts in terms of monitoring information on vaccine expiration issues and fraudulent vaccine record traces involving various vaccine supply chains such as the government. Blockchain technology with smart contracts, Internet of things (IoT), Artificial Intelligent (AI) and Big Data will be the technology that disrupts global supply chains, especially in SCF. IoT functions as a distributed input or sensor to collect real-time information relating to the position of goods, status and conditions to be sent digitally via the Internet. Then the blockchain technology acts as an eternal data store related to the supply chain process that is valid, safe and transparent [11,12].

The combination of the strengths of IoT and blockchain in presenting real-time information data on product visibility in the supply chain process has the potential to be a SCF solution such as inventory financing, purchase order financing and connections to other financial institutions. The main advantage of blockchain is a distributed ledger where related and encrypted transaction data is stored across all network members by public or private consensus security mechanisms, without a single unique authority. This consensus method offers relatively many technological advantages in terms of data architecture, durability, transparency, conservation, process integrity, security and validity $[13,14]$.

Smart contracts are defined as "computerized transaction protocols that execute contract terms" [15]. This smart contract is one of the advantages of blockchain technology that has the potential to be a SCF solution in terms of credit card validity, bill of lading, factoring and reverse factoring. This smart contract is relatively safe and transparent where sellers, buyers and financial institutions can copy encrypted ledger data because the distributed ledgers are guaranteed by modern cryptography [10]. This blockchain smart contract technology can also be operated automatically. Smart contracts are converted into data with a hash code, recorded, stored and executed automatically with an encryption key. This advantage provides a significant opportunity for SCF to automate financial transactions and payments in accordance with the time the physical transaction took place. Currently, this process is very difficult to implement due to lack of trust and difficulty in validating data related to inventory data and financial flows between related parties [16]. 
Several case studies and analysis of the impact of blockchain technology on operations and supply chain management present preliminary evidence of the use of blockchain technology in supply chain activities can increase transparency, accountability and resilience. In fact, the blockchain technology mechanism can help achieve the objectives of global supply chain management processes across national trade boundaries. Blockchain technology as electronic commerce driver has the potential to be applied in the logistics industry because it can systematically integrate, reduce risk, be more flexible, faster, traceable and transparent in presenting process information from customer requests to customer shipments [17-20].

However, the adoption of blockchain technology into SCF has encountered several obstacles such as doubts about the benefits of the technology, investment costs and complexity of knowledge of blockchain technology itself due to its novelty $[7,11,21]$. There needs to be a real case study of implementing blockchain technology adoption in SCF. So, the motivation of this research is to explore how the real implementation of blockchain technology and its practice solves problems in SCF. This study aims to explore how the adoption of blockchain technology in the current SCF process uses a multi-case method based on the Technological Acceptance Model (TAM) theory. This study uses TAM because the theory is successful in explaining various behaviors of adopting new technologies such as computers and the Internet in business [22]. The relatively new blockchain technology in SCF is considered suitable for analysis using TAM based on perceived usefulness and perceived ease of use $[17,21]$. Therefore, this study poses two researcher questions (RQ) with regard to the adoption of blockchain technology, as follows:

- RQ1: How does the perceived usefulness of blockchain technology resolve the issue of trust and transaction validity in the SCF process?

- RQ2: How does the perceived ease of use of blockchain technology solve the automation problem in SCF?

Then, this research also intends to explore the future direction of implementing blockchain technology in SCF. This study uses purposive sampling to collect and analyze 30 blockchain projects in SCF from a global supply chain network based on information from the World Trade Organization Forum.

This paper consists of the following: Section 1 explains the background of implementing blockchain technology in SCF. Section 2 provides an overview of the literature and theory related to SCF and the adoption of blockchain technology. Section 3 describes the research methodology used. Section 4 contains the results of a multi-case study of the current adoption of blockchain technology in SCF based on TAM. Section 5 presents a discussion of the research results. Lastly, Section 6 presents the conclusions, practical implications and suggestions for further research.

\section{Literature Review}

\subsection{The Development of Supply Chain Finance}

Supply Chain Finance (SCF) is defined as a process of optimizing working capital in the supply chain process involving various related parties. The parties involved in the SCF process include logistics, supply chain management, distribution collaboration and financial institutions that collectively create value. The SCF process is carried out through planning, directing and controlling financial flows between the organizations involved. From the definition of SCF, there are three main factors of SCF, namely: (1) working capital; (2) opening a trading account; (3) technology platforms. Working capital management has the objective of optimizing working capital with the target of shortening the cash-to-cash $(\mathrm{C} 2 \mathrm{C})$ cycle so that cash remains available to the company. This activity allows companies to release idle and unused capital to increase free cash flow, thereby increasing funding through internal companies which in turn can increase company value. SCF innovations offer suppliers the possibility of being paid early by external third parties (for example financial institutions, banks, investors or other parties). Meanwhile, this SCF innovation also provides opportunities for buyers to pay later so that buyers can better manage their 
working capital. With the solutions offered by SCF, parties involved in the supply chain can improve working capital management and create a win-win situation for all parties [2,3].

"Open Account" (O/A) trading is a common trading activity at this time due to intense competition for the export market, so buyers often pressure exporters to apply open account requirements (30-90 days). From the buyer's perspective, open account trading is more profitable because it requires lower costs and high flexibility compared to other forms of trade finance such as letters of credit (L/C) or bank payment obligations. However, from the supplier's perspective, this makes the supplier bear a greater risk and working capital. SCF's solution is to offer suppliers involved in trade flows alternative funding to mitigate this problem such as reverse factoring. SCF is considered a supply chain stakeholder approach to jointly create value through planning, directing and controlling the flow of financial resources with inventory considerations. Trade credits are key to inventory in supply chain management because delayed payments by credit receipts allow buyers to increase order quantities due to the effect of the time value of money. Credit transactions can be a valuable supply chain coordination tool in managing working capital $[4,5,16]$.

The technology platform is an important factor driving SCF activities that can bridge transaction data from various parties involved in the supply chain. Supply chain technology providers offer a platform that can connect all parties and facilitate the process of reconciliation, exchange of purchase orders, invoices, credit notes, payments and related information. Then, the platform also integrates information between different supply chain constituents. The bank's platform enables the flow of information from events that trigger the financing process of a dedicated SCF platform provider. Banks are more efficient at collaborating with experienced third-party technology platform providers than trying and developing internal solutions [2,6].

Previous SCF studies can be grouped into two main perspectives [7], namely: "financially oriented" focusing on solutions to deal with accounts payable and receivable, and "supply chain oriented" which focuses on optimizing working capital in the supply chain. SCF involves utilizing the supply chain process for financing, generating profits and managing assets efficiently which also benefits the parties involved along the supply chain as well as third parties. The function of SCF in financial terms is: (1) capital budgeting, (2) long-term financing decisions, and (3) working capital management with the ultimate goal of increasing shareholder value. SCF decisions can affect the company's capital structure, costs, profits, risks and market value of the company so that financial decisions affect the entire supply chain process and its stakeholders. Then, SCF can be seen as a combination of product and service strategies supported by technological solutions by involving financial institutions as financing providers $[8,9,23]$.

SCF uses financial instruments, mechanisms and technology to optimize the management of working capital and liquidity tied to the supply chain process for the parties involved. SCF is a series of isolated actions taken to optimize financial flows and working capital through the supply chain. SCF functions to create liquidity through buyer- or seller-led solutions to optimize the cost of capital in the supply chain. SCF's role is to connect various parties in transactions such as buyers, suppliers and financial institutions. The process is expected to be able to create a win-win solution so that all parties are willing to be involved. SCF allows buyers and suppliers to get short term credit to optimize their working capital, reduce finance costs and increase business efficiency.

One example of SCF is reverse factoring (RF). RF provides financial solutions for suppliers. The financier or third party will pay the supplier's receivables before the due date at a certain discount rate. RF is managed by the bank on the condition that the buyer and the buyer's supplier have credibility. The bank provides this facility even though it is possible that the supplier does not have financial records and limited assets that can be used as collateral. In an RF arrangement, credit-worthy buyers initiate the process and agree to the bank that they will immediately pay the invoice issued by the supplier. Then, if the supplier wants to be paid early, they can sell the invoice to the bank at a discount 
using the buyer's credit rating guarantee. Banks will collect information and calculate credit risk from the credibility of buyers such as internationally accredited companies [10].

With the help of technology, SCF also gave rise to innovations such as reverse factoring and dynamic discounts as financing arbitrage by utilizing different access to funding and capital costs for each participant along the supply chain such as buyers, sellers and financial institutions. The reverse factoring innovation provides opportunities for high-risk suppliers to transfer their credit risk to buyers who have high credit quality or low risk. This can reduce supplier problems if receivables from high quality buyers are considered as credit worthiness. In current practice, a buyer-led SCF model is more attractive to businesses because partner risks shift from suppliers to larger buyers. This large buyer usually has a better risk profile so that banks require lower costs to analyze credit risk profile information and can increase their profitability compared to other trade financial solutions $[4,11]$.

\subsection{Blockchain Technology Potential Adoption in SCF}

Blockchain technology records encrypted transactions in a ledger that is distributed to network members over a period of time. Each transaction record is entered into a data block and then each block is linked to the previous block using encryption and hashing functions. Encryption and hashing to fingerprint and digital data keys. Data is verified and managed using automation protocols and consensus governance. Verification is carried out by some or all members of the blockchain network because the ledger of all recorded transactions is distributed to all members of the network. If the majority of network members agree on a consensus that the signature and data history are valid, then the new block of transaction data is accepted into the ledger and added to the transaction block chain. The shared process of verification using modern encryption methods effectively secures data in the distributed ledger against unauthorized access or manipulation of data. This validation method ensures that network members always have access to traces of transaction activity, making it possible to perform comprehensive information audits. The advantage of blockchain technology also lies in the system's ability to correct data without requiring a third party as a data verifier but through a consensus method [12].

In general, there are two types of blockchain data access control mechanisms based on the involvement of network members in the consensus process. The first mechanism, a public blockchain, is a blockchain in which every transaction is publicly accessible but users can remain anonymous. The network has an open incentive mechanism to encourage more participants to join the consensus mechanism. The second mechanism is a blockchain with permissions, where network members must have permission to join the consensus on the network. Permissions or access control are controlled by a blockchain consortium or one particular organization or private blockchain [13].

Blockchain technology can also help improve security, service levels, reduce maintenance costs and ensure product authenticity. This is possible because blockchain technology operate in real time and are automatically able to provide information to the network via the Internet relating to the origin of materials, production processes, inventory levels, purchase orders, goods received, shipments, payments and invoices related to supply chain processes. Blockchain technology methods that can create smart contracts can match and verify transaction data from approval to payment. This smart contract system can automatically trigger other related transactions when transaction authorization is fulfilled, such as payment validation, product delivery permit and issuance of proof of delivery until product collection is confirmed or receipt of product by consumers is presented. All of these processes can occur automatically without manual intervention, thereby speeding up the supply chain process including automatic payments using digital currencies [14].

The blockchain technology architecture promises a supply chain data storage method with secure, irreversible and transparent access because the database is decentralized to many parties so that its authenticity can be evaluated consistently. This process allows decentralization of data so that no party can claim ownership of the supply chain data as their own. Data validation using the consensus method automatically validates or rejects 
data. When the benefits of this blockchain technology are combined with Internet of Thing (IoT), it has the potential to increase transaction speeds at a low cost. Every transaction data is verified by a consensus mechanism among network members. Then, it is fed into a cryptographically encrypted data block chain and distributed throughout the network members. After the merger, any related transaction data can be tracked, identified and validated at any time. This data block chain system maintains data validity by consensus from all or most network members [15].

In 2016, the Infocomm Development Authority of Singapore (IDA), Bank of America and HSBC stated that they had succeeded in building the Hyperledger Fabric blockchain application to speed up the letter of credit transaction process. The process replaces traditional L/C transactions with a blockchain system that allows information sharing between exporters, importers and banks involved on a permitted distributed ledger. Then a series of blockchain-based digital smart contracts enables automatic execution of deals. Figure 1 depicts blockchain revolutionizing trade finance in terms of the Letter of Credit process [16].

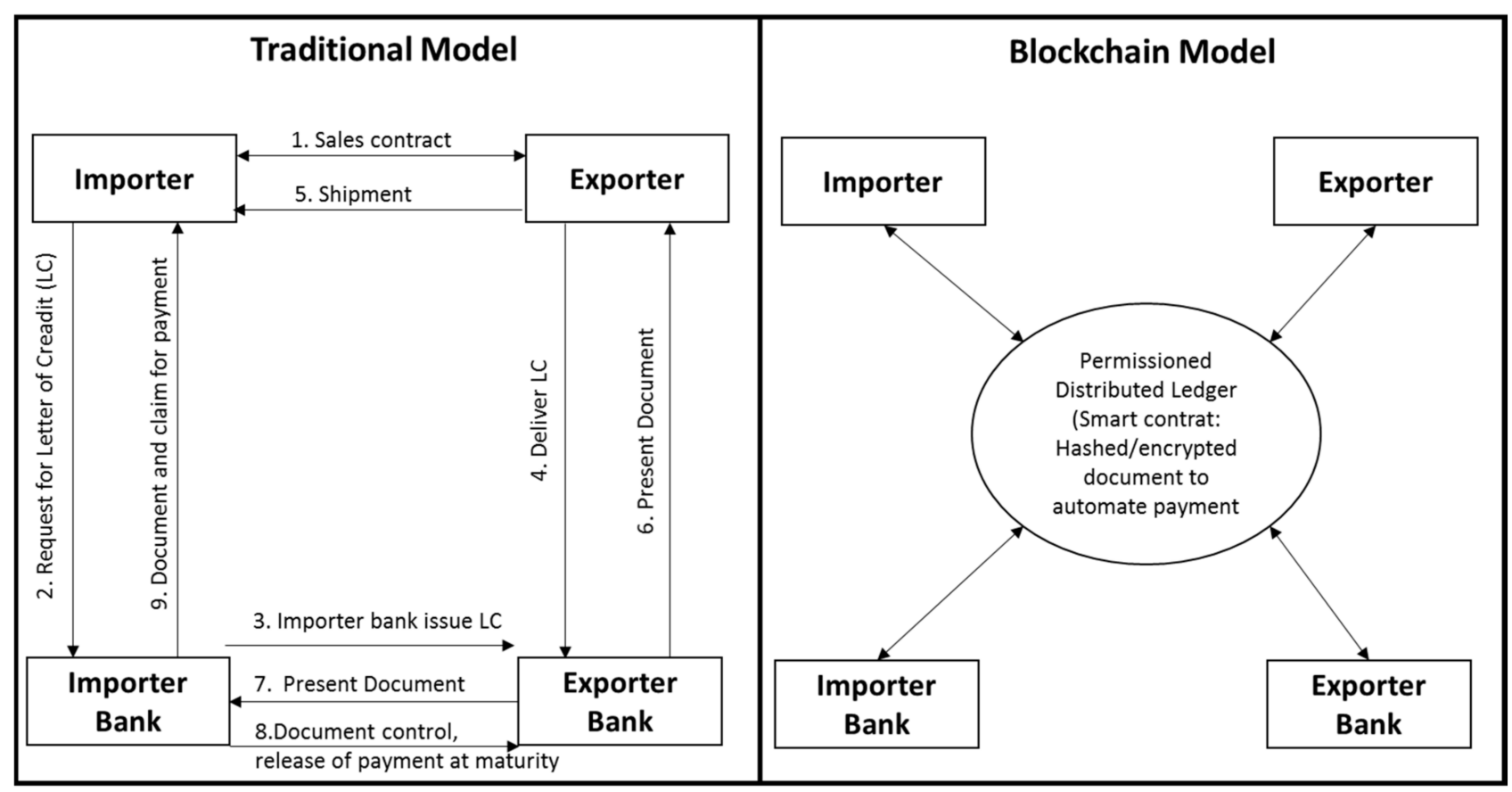

Figure 1. Blockchain can revolutionize trade finance: Letter of Credit process [16].

The advantages of blockchain technology which include (1) decentralized and secure databases, (2) anonymous and inexpensive transactions, and (3) smart contracts and product traceability are the main drivers of blockchain adoption. However, despite promising various benefits, the adoption of blockchain in supply chains, especially supply chain financing, is still in its infancy $[17,18]$. Besides the advantages, some of the barriers to adoption of blockchain technology are related to issues such as: (1) validation of successful adoption of blockchain technology, (2) integration with existing IT systems, (3) scalability, (4) lack of computing power, and (5) regulatory and legal governance [19].

Hofmann [20] identified the advantages of blockchain technology that have the potential to overcome three main obstacles in implementing SCF. First, Compliance Requirements (Know Your Customer-KYC). Blockchain record unique data with high-end encryption that can register the identity of perpetrators and transactions. Valid and secure KYC data checking makes the supplier chain process more effective and simple for financial institution like banks. Second, Standard Accounting Rules that compose the reconciliation of accounting standards from many stakeholders. These stakeholders include bank loans from various agreements between investors, sellers and buyers for the implementation 
of SCF. Blockchain can avoid reclassification when the deal process occurs because it will affect the accounting rules and audit methods used. The third, Issuance, Clearing and Settlement of trade. Issuance, clearing and settlement are important processes that require the involvement of various intermediaries who are responsible for matching records between buyers, sellers and financial institutions. Blockchain allows digital data from assets to be recorded directly into a distributed ledger. Smart contracts automatically store ownership details and transaction history, which can reduce risks associated with contract terms.

The successful implementation of blockchain technology can be seen in the TradeSafe project, a blockchain-based platform partnership created by a partnership between DBS Bank, Standard Chartered and Infocomm Development Authority Singapore. This project develops a "proof-of-perception" on blockchain-based invoice trading [16]. The invoice number and bill of lading number are used to generate a unique "hash" value that is recorded in an encrypted distributed ledger. Confidentiality of transaction invoice details is maintained and will not be visible to the rest of the network because the hash is just a unique set of characters as a key to unlock the encrypted record. So, if there are other banks that enter the same invoice data into the distributed ledger, it will produce the same "hash" value or one that is no longer unique. The transaction system will remind the second bank that the invoice is in the general ledger and has been used to apply for receivables financing. Therefore, this system serves to ensure and validate that the same bill or receivable will not be financed twice.

\subsection{Technology Adoption Model of Blockchain Technology: TAM}

The most widely used technology adoption model is the Technology Acceptance Model (TAM), which was adapted by Davis [24] from the Theory of Reasonable Action $[25,26]$. The model aims to explain the general determinants of technology acceptance based on the behavior of end users' beliefs about the technology adopted. The TAM model is based on two behaviors, namely: (1) Perceived Usefulness (PU) as the user's subjective belief that the use of a particular technology is beneficial, and (2) Perceived Ease of Use (PEU), which is related to the belief in the extent to which the ease of using technology has the potential to fulfill its goals. Venkatesh and Davis [22] demonstrated the finding that both perceived usefulness and perceived ease of use have a direct influence on behavioral intentions, thereby eliminating the need to build attitudes in Davis' previous model in 1989. Perceived usefulness is a factor that determines individuals' perceptions regarding the usefulness of new technologies in their lives. This factor is used to analyze individual acceptance of new technology. There is a positive relationship between perceived usefulness and behavioral intention to use technology [24,27-29].

Venkatesh and Davis [22] proposed TAM2 by adding two additional sets of processes to the previous TAM [24], namely, social influence and instrumental cognitive processes. Social influence is represented by (1) subjective norms, and (2) image. Then, instrumental cognitive processes are assessed on (3) job relevance, (4) output quality, (5) proven results, and (6) perceived ease of use. In this TAM2, they also add a moderating factor of experience and volunteerism. The results of the TAM2 empirical test show that users' mental judgments are related to the congruence between important goals at work and the consequences of performing job tasks using technology. These activities form the basis for forming perceptions about the usefulness of technology. TAM2 can best explain technology adoption in voluntary and mandatory environments.

Venkatesh [30] developed the Unified Theory of Acceptance and Use of Technology (UTAUT) to predict the adoption of technology users, especially information technology. UTAUT integrates eight theories: (1) TAM, (2) IDT, (3) reasoned action theory (TRA), (4) motivation model, (5) planned behavior theory (TPB), (6) TAM and TPB combination, (7) PC utilization model, and (8) social cognitive theory (SKT). However, the model becomes quite complex, as criticized by Van Raaij and Schepers [31]. Their criticism is that UTAUT is actually a complex system whose individual constructs are a combination of too many different factors. The explanatory power of $70 \%$ can be achieved by introducing an element 
of moderation. Thus, UTAUT's main model is inherently not much better than TAM or TAM2. So, in the study of technology adoption, they used the modified version of TAM2 to get better results rather than using the UTAUT model [30,31].

Folkinshteyn and Lennon [21] demonstrated the effectiveness of TAM in analyzing aspects of blockchain technology adoption by developers and end users. For both developers and end users, the positive factors in PU and PEU are that they are open source or free, have users as control and have transaction efficiency. However, the negative factors carry a number of risks, such as competent control requirements and not being too forgiving of mistakes. Blockchain technology in general can be adopted as a valuable supplement to financial technology and transaction recording but not as an overall replacement. TAM offers a good framework for advanced analysis of this evolving financial technology.

Singh [29] conducted a corporate governance survey research using TAM as a frame of reference for the blockchain technology adoption model. The analysis and hypotheses were prepared based on TAM [24] with perceived ease of use, perceived usefulness and attitudes of various stakeholders as the main factors of the acceptance model used in blockchain technology. The study found that almost all aspects of corporate governance can be improved through the adoption of blockchain technology. Improved governance includes, namely: (1) efficiency of administrative burdens; (2) better ownership transparency; (3) reduce fraud risk due to absolute audit trail; and (4) secure and accurate proxy voting [21,29].

Kamble [17] analyzed the possible adoption of blockchain technology using machine learning techniques based on the theoretical framework of Technology Acceptance Model (TAM) and Technology-Organization-Environment (TOE). The study found that the perceived usefulness and perceived ease of use of TAM theory are the factors that most influence the adoption of blockchain technology [32].

\section{Research Methodology}

The case study method focuses on exploring "how" and "why" questions that are very useful in the analysis of complex structures or new phenomena that are influenced by many factors so that explanations of reality are observed in more depth in accordance with the context and purpose of the observations [33-35]. The adoption of blockchain technology in the supply chain, especially SCF, is still relatively new and has the potential to solve many problems related to trust, transparency and data validation, including transaction automation processes. Therefore, this research used the case study method as a research method.

The case study selection process was carried out based on a targeted case by purposive sampling according to the needs and objectives of the study $[34,36]$. This study used a multiple case study method with the aim of exploring how the adoption of blockchain technology in SCF based on the technology acceptance model (TAM). Cases were selected and processed according to the case study procedure proposed by Yin [35,37]. Here, 30 cases were selected using purposive sampling with the following criteria: (1) the application of blockchain technology in solving problems in SCF, based on (2) perceived usefulness and (3) perceived ease to use. Each case was verified for validity and reliability using a cross check of information based on interviews, websites, social media and YouTube. The collection of information was then further processed using a qualitative comparative analysis (QCA) method with R-stat to analyze the criteria for perceived usefulness and perceived ease of use of blockchain technology in SCF.

We selected 30 blockchain projects as cases that represent the application of blockchain technology in SCF and their potential future direction. Sources of case information are taken from secondary data and analysis of public data information in the World Trade Organization (WTO) and the company's website. Cases were analyzed using the main TAM framework, namely: (1) Perceived Usefulness and (2) Perceived Ease of Use. The Perceived Usefulness analysis focuses on the usefulness of blockchain technology in overcoming the SCF problem raised by Hofmann [20], namely: (1) Requirements Compliance (KYC), (2) Accounting Rules and Treatment, and (3) Issuance, Clearing and Settlement. Then, the 
Perceived Ease of Use Analysis focuses on three opportunities blockchain technology can encourage the use of SCF in business, such as: (1) inventory financing, (2) purchase order financing, and (3) receivables financing.

\section{Results}

\subsection{Blockchain Technology Adoption in SCF: TAM}

Table 1 shows the summary of 30 blockchain projects implementing SCF from various countries. All of them put forward the novelty of technology that can provide efficient supply chain processes. The blockchain project is mostly trying to solve the main problems in the supply chain, namely: (1) the process of digitizing records, (2) acceleration of transactions, (3) security, (4) traceability, (5) transitions, (6) validation, and (7) regulatory compliance. Then, they offer supply chain activity innovations such as audit facilities, risk mitigation and alternative funding.

Table 1. Summary of 30 blockchain projects in SCF.

\begin{tabular}{|c|c|c|}
\hline Code & Blockchain Project & Keywords and Description \\
\hline $\mathrm{C} 1$ & AZHOS & $\begin{array}{l}\text { Production, inventory, transparency, payment of the } \\
\text { supplier's claim by the financier, repayment to the } \\
\text { financier by the customer. }\end{array}$ \\
\hline $\mathrm{C} 2$ & $\mathrm{~B} 2 \mathrm{P}$ & $\begin{array}{l}\text { Procurement, invoicing, supply chain, tracking, approval, } \\
\text { payments and eTax. }\end{array}$ \\
\hline $\mathrm{C} 3$ & Cargo & Smart bill of lading, document for global trade. \\
\hline $\mathrm{C} 4$ & ChainNova & L/C, bill of lading, invoice traceability. \\
\hline C5 & citrusxchange & Receivables financing and factoring. \\
\hline C6 & Contour (Voltron) & $\begin{array}{l}\text { Digital document, tracking, exchange documents, L/C, } \\
\text { trade finance cycle, trust, automation, supply chain } \\
\text { process. }\end{array}$ \\
\hline $\mathrm{C} 7$ & Digiledge & $\begin{array}{l}\text { Invoice factoring, audit trail, smart contract automation, } \\
\text { legacy credit scoring, ERPs, purchase order financing. }\end{array}$ \\
\hline $\mathrm{C} 8$ & ecomchain & $\begin{array}{l}\text { Financial asset transactions, digital credit records, inquiry, } \\
\text { payments, asset issuance, pricing inventory }\end{array}$ \\
\hline C9 & etradeconnect & $\begin{array}{l}\text { Financing trade, sharing data, security, and effective, } \\
\text { cost-efficient. }\end{array}$ \\
\hline $\mathrm{C} 10$ & Gatechain & $\begin{array}{l}\text { Electronic trade, automated export, smart factoring } \\
\text { solution. }\end{array}$ \\
\hline $\mathrm{C} 11$ & Geora & $\begin{array}{l}\text { Trusted records, integrated, IoT, asset backed finance, } \\
\text { smart contracts. }\end{array}$ \\
\hline $\mathrm{C} 12$ & Hijro & Financial operating network for global trade. \\
\hline $\mathrm{C} 13$ & Hyperchain & $\begin{array}{l}\text { Financing and splitting accounts receivable, low cost, } \\
\text { traceability. }\end{array}$ \\
\hline $\mathrm{C} 14$ & India Trade Connect & $\begin{array}{l}\text { Banking trade finance, } \mathrm{L} / \mathrm{C} \text {, transactions, bill collection, } \\
\text { exchange, } \mathrm{C} 2 \mathrm{C}, \mathrm{B} 2 \mathrm{C}, \mathrm{PO} \text { financing, invoice financing, } \\
\text { bank guarantee, and factoring. }\end{array}$ \\
\hline $\mathrm{C} 15$ & Komgo & $\begin{array}{l}\text { KYC, L/C, simplifying, interoperability, optimization, } \\
\text { security, exchange, banks, traders, inspection, certification, } \\
\text { receivable discounting. }\end{array}$ \\
\hline
\end{tabular}


Table 1. Cont.

\begin{tabular}{|c|c|c|}
\hline Code & Blockchain Project & Keywords and Description \\
\hline $\mathrm{C} 16$ & MarcoPolo & $\begin{array}{l}\text { Secure, distributed, bookkeeping, automated, identity, } \\
\text { verification, tracking, receivable finance, factoring, } \\
\text { payment commitment, risk mitigation. }\end{array}$ \\
\hline $\mathrm{C} 17$ & MonetaGo & $\begin{array}{l}\text { Fraud mitigation, supply chain finance, factoring } \\
\text { receivables, corporate certificates of deposits. }\end{array}$ \\
\hline $\mathrm{C} 18$ & Persitent Systems & $\begin{array}{l}\text { Audit trail, bill of lading, invoicing, document } \\
\text { verification. }\end{array}$ \\
\hline C19 & phlo & $\begin{array}{l}\text { P2P lending based on receivables, tracking, letter of credit, } \\
\text { bill of lading, digitization, provenance, trade automation. }\end{array}$ \\
\hline $\mathrm{C} 20$ & Skuchain & $\begin{array}{l}\text { Buyers and parties related to the supply chain are given } \\
\text { access to tight control of procurement and inventory. }\end{array}$ \\
\hline $\mathrm{C} 21$ & TangoTrade & $\begin{array}{l}\text { US based importers can borrow, payment assurance, } \\
\text { suppliers global. }\end{array}$ \\
\hline $\mathrm{C} 22$ & TradeCloud & $\begin{array}{l}\text { KYC procedure, contracts, services, shipping documents, } \\
\text { Letter of credit }(\mathrm{L} / \mathrm{C}) \text {. }\end{array}$ \\
\hline $\mathrm{C} 23$ & TradeFinanceMarket & $\begin{array}{l}\text { Invoice fraud mitigation, double-financing checking, } \\
\text { trade finance market. }\end{array}$ \\
\hline $\mathrm{C} 24$ & TradeFinex & Invoice factoring. \\
\hline $\mathrm{C} 25$ & Tradelens & $\begin{array}{l}\text { Trust, transparent supply chain, transportation, shipment, } \\
\text { tracking, permission-based sharing. }\end{array}$ \\
\hline $\mathrm{C} 26$ & TradeLine & L/C, Pre and Post trade workflow for commodity trading. \\
\hline $\mathrm{C} 27$ & Tradewind & $\begin{array}{l}\text { Digital trading, settlement, ownership, integration, } \\
\text { invoice financing. }\end{array}$ \\
\hline $\mathrm{C} 28$ & Trado & $\begin{array}{l}\text { Direct purchase order financing, savings from an } \\
\text { end-buyer to smallholders. }\end{array}$ \\
\hline $\mathrm{C} 29$ & We.Trade & $\begin{array}{l}\text { KYC, order-to-payment, invoice financing, trade deal, } \\
\text { SMEs trading, invoice financing, bank payment } \\
\text { undertaking, shareholders bank. }\end{array}$ \\
\hline $\mathrm{C} 30$ & Zeor1 & $\begin{array}{l}\text { Funding with the production cycle, adjusting price, } \\
\text { suppliers leverage credit worthiness. }\end{array}$ \\
\hline
\end{tabular}

\subsection{Perceived Usefulness: Blockchain Technology Overcomes SCF Problems}

Table 2 shows a summary of the implementation of the blockchain project and the solutions offered to overcome obstacles in the SCF. Of the three obstacles to implementing blockchain in SCF, KYC problem solving is the most offered feature (27 of 30 blockchain projects). Then, the issue of appropriateness of accounting treatment, reporting and auditing became the second feature offered most often ( 27 of 30 blockchain projects). Meanwhile, with the issuance, clearing and settlement features, only six blockchain projects in SCF provide this facility. The six projects collaborate with the capital market, trade regulators and the banking industry. However, there are also those who open securities markets that are specific to financial supply chains such as the Marcopolo platform with its TradeIX. 
Table 2. Blockchain projects' features for overcoming barriers in SCF.

\begin{tabular}{|c|c|c|c|c|}
\hline \multirow{2}{*}{ Code } & \multirow{2}{*}{ Blockchain Project } & \multicolumn{3}{|c|}{ Supply Chain Finance (Barriers) } \\
\hline & & KYC & Accounting & Clearing and Settlement \\
\hline $\mathrm{C} 1$ & AZHOS & $\mathrm{V}$ & - & - \\
\hline $\mathrm{C} 2$ & B2P & $\mathrm{V}$ & $\mathrm{V}$ & - \\
\hline $\mathrm{C} 3$ & Cargo & - & $\mathrm{V}$ & - \\
\hline $\mathrm{C} 4$ & ChainNova & $\mathrm{V}$ & $\mathrm{V}$ & - \\
\hline C5 & citrusxchange & - & $\mathrm{V}$ & - \\
\hline C6 & Contour (Voltron) & $\mathrm{V}$ & $\mathrm{V}$ & $\mathrm{V}$ \\
\hline $\mathrm{C} 7$ & Digiledge & $\mathrm{V}$ & $\mathrm{V}$ & $\mathrm{V}$ \\
\hline $\mathrm{C} 8$ & ecomchain & $\mathrm{V}$ & $\mathrm{V}$ & $\mathrm{V}$ \\
\hline C9 & etradeconnect & $\mathrm{V}$ & - & - \\
\hline $\mathrm{C} 10$ & Gatechain & $\mathrm{V}$ & - & - \\
\hline $\mathrm{C} 11$ & Geora & $\mathrm{V}$ & $\mathrm{V}$ & - \\
\hline $\mathrm{C} 12$ & Hijro & $\mathrm{V}$ & $\mathrm{V}$ & - \\
\hline $\mathrm{C} 13$ & Hyperchain & $\mathrm{V}$ & $\mathrm{V}$ & - \\
\hline $\mathrm{C} 14$ & India Trade Connect & $\mathrm{V}$ & $\mathrm{V}$ & - \\
\hline C15 & Komgo & $\mathrm{V}$ & $\mathrm{V}$ & - \\
\hline $\mathrm{C} 16$ & MarcoPolo & $\mathrm{V}$ & $\mathrm{V}$ & $\mathrm{V}$ \\
\hline $\mathrm{C} 17$ & MonetaGo & $\mathrm{V}$ & $\mathrm{V}$ & - \\
\hline $\mathrm{C} 18$ & Persitent Systems & $\mathrm{V}$ & $\mathrm{V}$ & - \\
\hline C19 & phlo & $\mathrm{V}$ & $\mathrm{V}$ & - \\
\hline $\mathrm{C} 20$ & Skuchain & $\mathrm{V}$ & - & - \\
\hline $\mathrm{C} 21$ & TangoTrade & $\mathrm{V}$ & $\mathrm{V}$ & - \\
\hline $\mathrm{C} 22$ & TradeCloud & $\mathrm{V}$ & - & - \\
\hline $\mathrm{C} 23$ & TradeFinanceMarket & $\mathrm{V}$ & $\mathrm{V}$ & - \\
\hline $\mathrm{C} 24$ & TradeFinex & - & $\mathrm{V}$ & - \\
\hline $\mathrm{C} 25$ & Tradelens & $\mathrm{V}$ & $\mathrm{V}$ & - \\
\hline $\mathrm{C} 26$ & TradeLine & $\mathrm{V}$ & $\mathrm{V}$ & - \\
\hline C27 & Tradewind & $\mathrm{V}$ & $\mathrm{V}$ & V \\
\hline C28 & Trado & $\mathrm{V}$ & - & - \\
\hline C29 & We.Trade & $\mathrm{V}$ & V & $\mathrm{V}$ \\
\hline C30 & Zeor1 & $\mathrm{V}$ & $\mathrm{V}$ & - \\
\hline & Total: & 27 & 24 & 6 \\
\hline
\end{tabular}

\subsubsection{Blockchain Usefulness for Compliance Requirements (KYC) Problem}

Know Your Customer (KYC) is a procedure performed by financial institutions such as banks to avoid money laundering, crime and terrorism by tracking prospective customer records and transactions. Table 2 shows that, of the 30 blockchain projects in SCF, 27 projects listed the benefits of tracking identity and transaction data on their platforms. They offer KYC facilities and identity tracking to those in need. The KYC project usually works with financial institutions such as banking. The advantages of this blockchain technology are already broadly applied to platforms that offer SCF.

The blockchain trading financing from Contour (C6) is complemented by various project missions for banks and companies. The bank uses an open and decentralized blockchain trading financial system from Contour (C6) so that the bank can track exporters, importers and other trade participants in the KYC process.

The KYC proposal from We.Trade (C29 in Table 2) aims to provide services to banks in the ecosystem to obtain transparent and integrated data, visibility of end-to-end trade transactions and transaction coordination centers involving many parties involved. The uniqueness offered by We.Trade (C29) is a facility to find trade partners and documents related to trade. This uniqueness can be obtained because all the We.Trade (C29) clients are screened by their banks spread across various countries, and the payment risk is borne by them. This can be done because We.Trade (C29) was built by major banks in Europe such as Deutsche Bank, HSBC, Rabobank, Erste Group, KBC, Natixis, Nordea, Santander, Société Générale, UBS, CaixaBank and UniCredit. 
In contrast to We.Trade (C29) built by a banking consortium, the TradeCloud (C22) blockchain system works with Inacta, a company that has specifically developed integrated blockchain-based solutions that allow KYC and AML (anti-money laundering) to be carried out efficiently.

Figure 2 shows another example of KYC implementation by the Persitent Systems (C18) platform that offers blockchain technology solutions for managing KYC from financial institutions. This system has integrated data that is safe and cannot be changed so that every line of business in a financial institution can conduct customer checks quickly. New customers usually provide KYC documents every time they need services from different bank business lines in the same bank. To maintain the confidentiality and privacy of customer documents, the bank's business lines cannot easily share customer KYC information with others so that it takes a long time and high operational costs for opening new accounts.

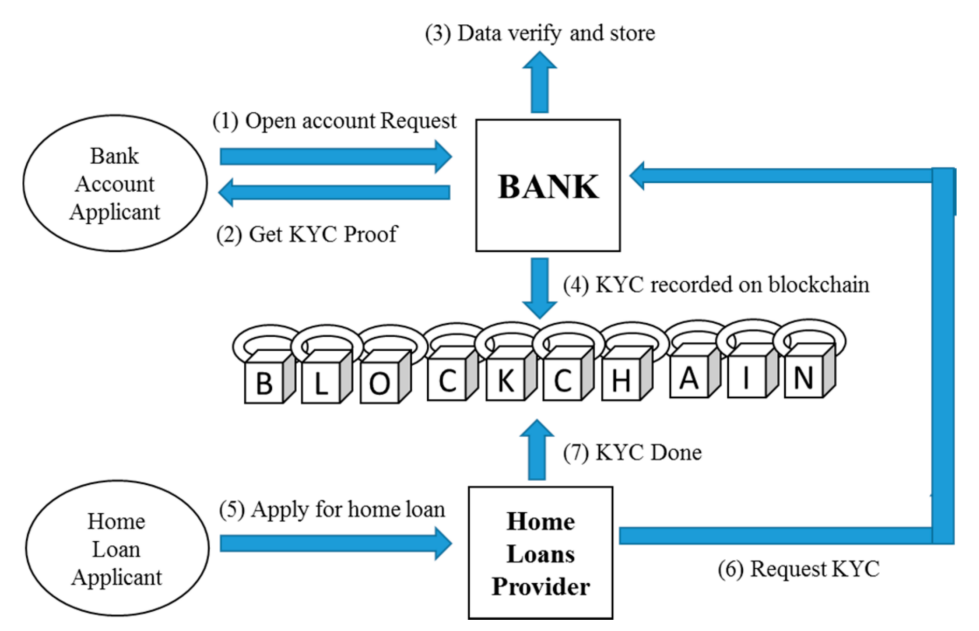

Figure 2. KYC information process on the Persitent Systems (C18) blockchain ecosystem [38].

With the help of blockchain technology from Persitent Systems (C18), the bank enables its business lines to securely share and exchange KYC information with audit trails recorded on blockchain data. This blockchain-based solution enables bank business lines to securely search customer information and verify and store validated customer data. With the help of AI, the blockchain system can also share warnings when customer data is changed or used not according to applicable procedures.

\subsubsection{Blockchain Usefulness for Accounting Rules and Treatments Problem}

The main feature of the blockchain technology application is that it deals with data that cannot be changed, it operates real time, is transparent and automatically validated so as to reduce audit costs. The availability of data combined with AI technology in data analysis will make accounting activities faster and more reliable. The blockchain project mostly offers these features as an advantage to their clients including auditing related to SCF.

For example, in Table 2, Digiledge (C7) is a blockchain company that offers solutions for banking, insurance and supply chains using IoT and Artificial Intelligence, and includes auditing and other accounting activities. Blockchain-based procurement applications help companies handle procurement business processes ranging from purchasing to planning, approvals, purchase orders, smart contract clauses, purchase receipts, tracking various related reports and finally creating invoices. All of these activities are recorded into the blockchain system to improve business process efficiency, trustworthiness, fast audit paths and fact reconciliation in real time. Then, in the verification and handling of transaction data, the Digiledge (C7) application helps end customers verify and track possible fraud 
such as falsification of signatures and will contact the issuing bank using a decentralized network.

The Marcopolo (C16) blockchain platform (in Tables 1 and 2) also offers superior audit problems because real-time visibility, validation and data distribution automatically become a single source of transaction data truths that enable accounting and audit compliance systems in accordance with applicable regulations. Transaction-level privacy allows companies to manage data in accordance with accounting rules and to work with ERP used such as Oracle, SAP and Microsoft Dynamics. This method can be easily integrated with the applicable accounting system.

\subsubsection{Blockchain Usefulness for Issuance, Clearing and Settlement Problem}

Issuance, clearing and settlement are processes that require various intermediaries. The main task of this intermediary relies on matching the records of buyers, sellers and confirmation that the partner agrees with the terms and fulfills the delivery requirements, then exchanges securities for cash involving trusted third parties. Blockchain technology has the potential to accelerate this process, but because many parties are involved, the implementation is still limited to a large trade consortium or supported by banks and regulators.

From Table 2, we can compare that the We.Trade (C29) blockchain platform promises real-time trade settlement enabled by a single platform for all relevant parties such as banks and regulators. Then, etradeconnect also facilitates trade settlement and financing by way of sharing trade data through a secure blockchain-based trading finance platform. Furthermore, Marcopolo (C16) blockchain offers fast transactions, settlement processing, working capital cycle efficiency, risk mitigation and financing in one blockchain platform. In 2018, the Countur (C6) platform used the Corda (R3) blockchain to complete a letter of credit transaction for shipping soybeans from Argentina to Malaysia for US group Cargill.

\subsection{Perceived Ease of Use: Blockchain Simplifies the Process of Inventory Financing, Purchase Order Financing and Receivables Financing}

Table 3 shows a summary of the implementation of the blockchain project and the solutions offered to drive developments in the SCF. Receivables financing is the most offered ( 21 of 30 blockchain projects in SCF). This is in line with the current condition where most companies use receivables financing because the process is in the final stages of the supply chain, so it is expected to provide a relatively smaller risk than other financing schemes. After receivables financing, purchase order financing is ranked second, offered by 15 blockchain projects in SCF. Meanwhile, there are only eight inventory financing projects because the possibility of the risk is considered greater. From these results it can be seen that blockhain technology cannot be utilized to the maximum of its superior capacity. With the recording feature, every process in a transaction in the supply chain should reduce the risk because the information is trusted, transparent and has validity guaranteed. Inventory financing should be able to develop more rapidly in the future.

Table 3. Blockchain projects that simplify the process of inventory, purchase order and receivables financing in SCF.

\begin{tabular}{ccccc}
\hline \multirow{2}{*}{ No } & \multirow{2}{*}{ Blockchain Project } & \multicolumn{3}{c}{ Supply Chain Finance (Financing) } \\
\cline { 3 - 5 } & & Inventory & Purchase Order & Receivables \\
\hline C1 & AZHOS & $\mathrm{V}$ & - & $\mathrm{V}$ \\
C2 & B2P & $\mathrm{V}$ & - & $\mathrm{V}$ \\
C3 & Cargo & - & $\mathrm{V}$ & - \\
C4 & ChainNova & - & - & $\mathrm{V}$ \\
C5 & citrusxchange & - & - & $\mathrm{V}$ \\
C6 & Digiledgde & - & $\mathrm{V}$ & $\mathrm{V}$ \\
C7 & ecomchain & $\mathrm{V}$ & - & - \\
\hline
\end{tabular}


Table 3. Cont.

\begin{tabular}{|c|c|c|c|c|}
\hline \multirow{2}{*}{ No } & \multirow{2}{*}{ Blockchain Project } & \multicolumn{3}{|c|}{ Supply Chain Finance (Financing) } \\
\hline & & Inventory & Purchase Order & Receivables \\
\hline $\mathrm{C} 8$ & etradeconnect & - & - & $\mathrm{V}$ \\
\hline C9 & Gatechain & - & - & $\mathrm{V}$ \\
\hline $\mathrm{C} 10$ & Geora & $\mathrm{V}$ & - & - \\
\hline $\mathrm{C} 11$ & Hijro & - & - & $\mathrm{V}$ \\
\hline $\mathrm{C} 12$ & Hyperchain & - & - & $\mathrm{V}$ \\
\hline $\mathrm{C} 13$ & India Trade Connect & - & $\mathrm{V}$ & $\mathrm{V}$ \\
\hline $\mathrm{C} 14$ & Komgo & - & $\mathrm{V}$ & $\mathrm{V}$ \\
\hline C15 & MarcoPolo & - & $\mathrm{V}$ & $\mathrm{V}$ \\
\hline $\mathrm{C} 16$ & MonetaGo & - & $\mathrm{V}$ & $\mathrm{V}$ \\
\hline $\mathrm{C} 17$ & Persitent Systems & - & - & $\mathrm{V}$ \\
\hline $\mathrm{C} 18$ & phlo & - & - & $\mathrm{V}$ \\
\hline C19 & Skuchain & $\mathrm{V}$ & - & - \\
\hline $\mathrm{C} 20$ & TangoTrade & - & $\mathrm{V}$ & - \\
\hline $\mathrm{C} 21$ & TradeCloud & - & $\mathrm{V}$ & - \\
\hline $\mathrm{C} 22$ & TradeFinanceMarket & - & - & $\mathrm{V}$ \\
\hline $\mathrm{C} 23$ & TradeFinex & - & - & $\mathrm{V}$ \\
\hline C24 & Tradelens & - & $\mathrm{V}$ & - \\
\hline $\mathrm{C} 25$ & TradeLine & - & $\mathrm{V}$ & - \\
\hline $\mathrm{C} 26$ & Tradewind & $\mathrm{V}$ & $\mathrm{V}$ & $\mathrm{V}$ \\
\hline $\mathrm{C} 27$ & Trado & $\mathrm{V}$ & $\mathrm{V}$ & - \\
\hline C28 & Voltron & - & $\mathrm{V}$ & $\mathrm{V}$ \\
\hline C29 & We.Trade & - & $\mathrm{V}$ & $\mathrm{V}$ \\
\hline C30 & Zeor1 & $\mathrm{V}$ & $\mathrm{V}$ & $\mathrm{V}$ \\
\hline & Total: & 8 & 15 & 21 \\
\hline
\end{tabular}

\subsubsection{Blockchain Simplifies Inventory Financing}

Inventory financing is an activity of a third party such as a bank that specifically provides financing with collateral in the form of products or property during the transportation and storage process. Financing activities in this way optimize the accounts receivable and trade payables of the company in the process of moving products so that they no longer have to keep these assets in their balance sheets but are still physically used for the production process. After the finished products that are stored are sold, the bank as the lender is paid for the loans they provide. If not sold, the bank can prove ownership of the assets that have been financed as collateral to be sold and the results are used as capital recovery given. With blockchain-based technology, inventory financing activities can create an asset ownership system that issues digital ownership certificates or "tokens" of assets financed by financial institutions. The financial institution as a lender can claim if there is non-repayment by showing the token owned and conducting asset sales activities. This activity is recorded in the blockchain system, and the exchange is recognized and legally accepted.

From Table 3, it appears that blockchain projects related to the implementation of inventory financing methods are still relatively small (8 out of 30 blockchain projects in SCF). This is likely because inventory financing is a financing instrument that has a higher intrinsic risk than invoice-based financing because investors are involved in the early stages of the transaction process in the supply chain. Then, the risk factor is represented by the problem of selling power and high durability of the goods inventory guaranteed from time to time. Blockchain technology can be a solution that minimizes the risk of inventory financing because it can record all production and inventory activities from producers, sellers to buyers. Production activities that use the blockchain system offer the opportunity to connect various users across the network to maintain the integrity of the warehouse status and receipt data. This can avoid the problem of data forgery or "double item expenditure". 
Skuchain (C19) blockchain platform can be an example of successful implementation of blockchain-based inventory financing (in Tables 1 and 3). Skunchain (C19) offers solutions for supply chain financing and, in particular, inventory financing. This Skunchain (C19) strategy is based on the experience of implementing a financial transaction transaction system with Wells Fargo, Commonwealth Bank of Australia and Brighann Cotton as the company's first project in using the blockchain for supply chain transactions. Skunchain (C19) considers that instead of suppliers taking financing through receivables which are usually very expensive, they do buy inventory directly with funds from the buyer's capital costs. From the supplier side, they get direct working capital assistance. From the buyer side, they get lower goods costs, and both parties benefit. This strategy provides a win-win solution so that the wheels of business turnover will be smooth.

Blockchain technology implemented by Skuchain (C19) allows stakeholders in the supply chain ecosystem to finance transactions using the inventory financing method. Third party financiers will not be willing to assume off-line transactions because they cannot see a clear record of the rights chain of the transaction in progress. Blockchain technology becomes a transparent and validated transaction data tracking solution from suppliers to Skuchain (C19) to buyers. Third party financiers can also see guaranteed payments from buyers in the blockchain system.

From the results of the implementation in Table 3, Skuchain (C19) established a Special Purpose Vehicle (SPV) named IMT (Inventory Management and Trading Services), with the aim of providing ease of supply chain financial transactions for buyers to directly purchase inventory from suppliers. The buyer can keep it as long as the buyer needs it, and it is recorded in the blockchian system so that when he uses the inventory, the blockchain system of Skuchain (C19) sells it back to him. The financial benefit of the activity is that suppliers get paid immediately and buyers can store their book inventory according to their needs. Suppliers also avoid the scheme of paying high interest receivable financing, which, in the case of Skuchain, ranges from $8 \%$ to $15 \%$, or even $30 \%$ in developing countries.

Blockchain technology implemented by Skuchain (C19) allows stakeholders in the supply chain ecosystem to finance transactions using the inventory financing method. Third party financiers will not be willing to assume off-line transactions because they cannot see a clear record of the rights chain of the transaction in progress. Blockchain technology becomes a transparent and validated transaction data tracking solution from suppliers to Skuchain (C19) to buyers. Third party financiers can also see guaranteed payments from buyers in the blockchain system and can reduce the risk of funding. In terms of the cost of the process, Skuchain (C19) takes a platform cost with a dynamic pricing scheme based on the specific provisions of each company transaction which is cheaper than other funding arrangements.

In the case of Skuchain (C19), inventory funding comes from third party investors, namely, commercial banks and individual investors with a syndicated loan funding structure. Skuchain (C19) issues a credit revolver with a number of third-party financiers and gives prices dynamically through an auction process for each individual investor transaction. This process can reduce interest rates and open market opportunities because Skuchain (C19) is a technology platform that is not bound by the same rules that must be obeyed by banks, so they can conduct transactions that cannot be guaranteed by banks. The advantages of blockchain technology such as security, transparency and validity of transaction data enable Skuchain (C19) to carry out financing transactions that are not guaranteed by banks while taking the trust of banks and individual investors.

Another example of inventory financing with blockchain technology shown in Table 3 is the Tradewind (C26) project. With the help of blockchain technology, Tradewind (C26) offers a global financing program based on blockchain technology that supports supply chain financing facilities based on debt, accounts receivable and inventory to align the needs of buyers and sellers throughout the supply chain. Specifically for inventory financing, Tradewind (C26) offers this solution only for clients with criteria: (1) goods that have a large market share, (2) goods easily sold, and (3) goods stored in reputable third-party 
warehouses. Tradewind (C26) can arrange financing of existing inventory with third parties. This inventory financing is usually governed by provisions on the level of advances, funding periods and good liquidation reserve planning according to the agreement. All inventory financing activities are recorded and validated in the blockchian system so that all parties involved can carry out checks and assessments.

\subsubsection{Blockchain Simplifies Purchase Order Financing}

In purchase order (PO) financing, funding occurs before the shipment of goods occurs and the third party that finances has the potential to bear a higher risk because the PO is the initial stage of the supply chain process. Financing purchase orders include the cost of raw materials, production and shipping. Therefore, blockchain technology is a solution for the transparency and validity of production, packaging and shipping process data so that third parties who will fund can make a reasonable assessment according to the stage of the process that occurs.

Tables 1 and 3 show that India Trade Connect (C13) is an example of a blockchain technology-based project that offers purchase order financing facilities. Blockchain network and technology in India Trade Connect (C13) is designed to digitize all financial trade business processes such as ownership validation, document certification and making payments with transaction data distributed to the trading network. The blockchain-based network creates new business opportunities for participating banks. In addition, this blockchain system also eliminates inefficiencies in the existing trading process so that it allows all people involved in transactions to have a secure and reliable data source.

The blockchain system helps financial institutions to record and consider financing decisions that are more informative because the banks involved in the transaction know the exact billing position including the company's exposure to each partner bank. India Trade Connect (C13) offers financing functions, including PO financing and invoice financing.

\subsubsection{Blockchain Simplifies Receivables Financing}

Receivables financing is a financing activity to finance supplier receivables. This receivables or invoice-based financing method is the most commonly used financing scheme. In receivables financing, risk measurement is strongly influenced by the creditworthiness of the supplier. Thus, funding costs are usually higher if the supplier's credit rating is worse than the buyer's credit rating because it is rated as riskier. Financial institutions such as banks usually become third parties who provide funds by buying receivables from suppliers. However, in the process of financing receivables, the financier must evaluate the creditworthiness of suppliers and buyers to determine the price and size of the financing. Blockchain technology that provides transparency and validity of reliable data can help speed up the process.

From Table 3, it appears that the method of financing receivables is the financing that has most adopted blockchain technology, namely, 21 of the 30 blockchain-based projects in SCF. An example of blockchain-based receivables financing is Komgo (C14). Komgo (C14) is a platform whose main aim is to digitize and improve trading processes supported by commodity finance. The initial shareholders of the Komgo (C14) project included major companies in trade and finance, namely, Citi, Rabobank, MUFG Bank, ABN Amro, BNP Paribas, Crédit Agricole, Gunvor, ING, Koch, Macquarie, Mercuria, Natixis, Shell, SGS and Société Générale. Komgo (C14) is expected to be able to utilize blockchain technology to simplify the agreement process and accelerate the commodity trading process so that investors can take advantage of trading transactions with clients or other parties.

Komgo (C14) launched a smart contract with the format L/C to include an automatch function so as to accelerate the issuance of $\mathrm{L} / \mathrm{C}$. This facility will support receivable financing, which is receivables discounting solution integrated with insurance. This process is possible using blockchain technology because all parties can monitor the progress of operations in real time, easily verified data, avoid fraud and shorten the cash cycle. 
Blockchain technology for financing recevables has also penetrated SMEs, such as the Hyperchain (C12) platform in China (in Tables 1 and 3). Hyperchain (C12) focuses on providing financing solutions for small and micro companies in the supply chain. Hyperchain (C12) creates a multi-level system that relies on the transfer of trust from the main company, around the main company, the company in the supply chain from upstream to downstream. Then, Hyperchain (C12) works with banks, confirmation agencies and other service providers involved in the ecosystem to create an ecological closed loop of the industry for supply chain finance and reduce the cost of funding for SMEs.

The blockchain network system was built with the concept of sharing information security, visualization of supply chain finance and SME financing by relying on credit transmission from major companies. Hyperchain (C12) created a supply chain service platform, "Moom", which provides information services for accounts receivable entities and uses the standard digital asset certificate, "Golden Ticket". This method can realize the online circulation of financing and the separation of accounts that have the advantage of low cost and high traceability. Hyperchain (C12) also created the "Ximei" factoring supply chain platform dedicated to creating a broader industrial supply chain ecosystem, effectively linking commercial credit and financial institutions. In addition, Hyperchain (C12) created a receivables chain platform in collaboration with Zhejiang Commercial Bank and Qulian Technology. This platform helps small businesses to issue, receive, confirm, pay, transfer, and guarantee cash receivables online via mobile phone. Hyperchain (C12) relies on security and distributed ledgers on the blockchain so that accounts receivable from companies are used as an online payment settlement, a way of financing to help companies reduce transaction costs.

\section{Discussion}

Blockchain technology has the potential to overcome obstacles in implementing SCF in business activities in the field. "Know Your Customer" (KYC) barriers, which are the main requirements in the international financial industry, can already be overcome by the advantage of blockchain in the record that cannot be changed, data security and automatic validation [39]. If the consumer data system can be incorporated into a blockchain-based international network, the KYC process can be done quickly and reliably. If $\mathrm{KYC}$ is done quickly, the supply chain financing process will be faster.

Blockchain technology can also solve the problem of accounting and auditing standards that are quite complex in the supply chain when combined with AI technology. The blockchain can act as a trusted and reliable data provider, and AI technology will make the system work automatically, adjusting accounting standards that vary between companies and countries. This process is very helpful for SCF activities, especially financing high-risk inventories and those that require reliable data.

Blockchain technology is perhaps most needed in issues of publishing, clearing and settlement, given the complexity of the trading process. The combination of blockchain and $\mathrm{AI}$ can be a solution because the differences in regulations and policies in each party involved must adjust to regulations. Blockchain and AI technology have the potential to drive SCF activities more quickly and massively. The advantage regarding transparency, security and data validity is that it enables financing schemes based on inventory, purchase orders and receivables to be done automatically. Then, simulating the best financing schemes for looking for the best financing can also be done in real time $[32,40]$.

The results of this study indicate that blockchain technology can accelerate the supply chain process. This is also in line with the research of Lahkani [41], who conducted research on the adoption of blockchain technology integrated with e-commerce supply chains in China. The use of blockchain increases supply chain efficiency by $74 \%$ and summarizes digital documentation by $75 \%$ over the previous process. Blockchain offers stakeholders in the supply chain an integration of business processes with the volume and control of large amounts of transaction data. Then, the blockchain integrated solution is linked into the 
global supply chain for B2B (Business-to-Business) to increase the firm's profitability and competitiveness.

The potential benefits and advantages of blockchain technology in global supply chains, especially automation, security and trustworthiness of transaction data will drive the rapid adoption of this technology in the future. Based on data from Statista [42], corporate spending globally on blockchain technology from 2017 to 2021 continues to increase. This shows that the adoption of blockchain technology in business, including SCF as a whole, is predicted to continue to increase. The estimated data (Figure 3) shows that companies' expenditure on blockchain technology implementation will reach USD 19 billion in 2024 . This expenditure shows an increase of 188\% from 2021, which was only USD 6.6 billion. The increase in spending shows the rapid adoption of blockchain technology, especially in terms of perceived usefulness and perceived ease of use.

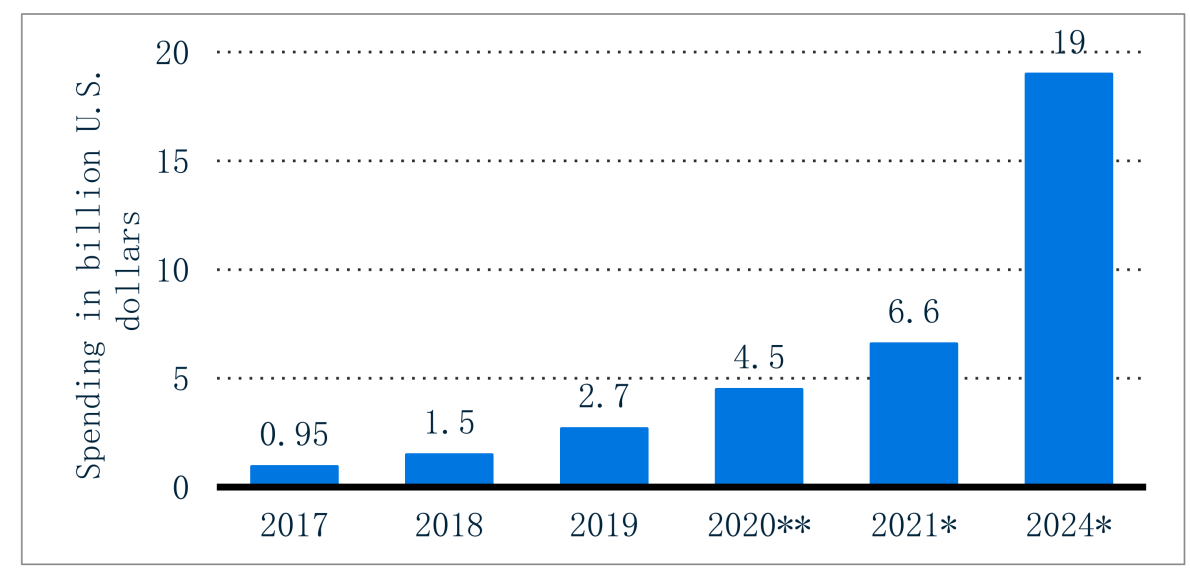

Figure 3. Worldwide spending on blockchain solutions from 2017 to 2024 (in billion U.S. dollars). Source(s): Statista; ID 800426 [42], * Forecast, ** 2020 was calculated based on the CAGR.

In addition to the potential and research that supports the adoption of blockchain technology, several studies also cast doubt on the success of blockchain implementation in supply chains. For example, Babich and Hilary [43] stated that the application of blockchain technology is still variable and unstable, thus suggesting caution not to fall into the "blockchain hype". The argument is that blockchain is still emerging and most projects are expected to fail as the role of censors and trusted auditors is still needed. Then, Sternberg [44] also sees very few successful implementations of blockchain technology solutions (BCT) in supply chains, as there is still little known empirically about the barriers to blockchain adoption especially in supply chain organization inter-organizational arrangements. This is because the decision to adopt and integrate blockchain technology from supply chain actors recursively affects the technology adoption decisions of other supply chain actors. On the other hand, apart from criticizing blockchain adoption, Babich and Hilary [43] realized the potential of blockchain technology in providing visibility, validation, contract automation, and security. This process can create a more transparent, efficient and secure supply chain, thus facilitating supply chain and financial integration. Both studies emphasize the lack of empirical and case studies regarding the actual implementation of blockchain technology in global supply chains.

\section{Conclusions}

From the analysis of 30 blockchain projects in SCF using TAM theory, it can be concluded that perceived usefulness drives the adoption of blockchain technology because it can solve SCF's main problems, namely: Know Your Customer (KYC), accounting and settlement. Then, blockchain technology also provides perceived ease to use with transaction automation features and smart contracts that are very suitable for solving 
fundamental barriers in supply chain financing such as (1) inventory financing, (2) purchase order financing, and (3) receivables financing.

The advantages of blockchain in solving problems in SCF are able to answer the perceived usefulness of TAM theory. Then, the ability of smart contracts to streamline the documentation and transaction processes thereby drives efficiency, which in turn reduces the cost of answering TAM theory, which is considered easy to use [17]. This is in accordance with the findings of Singh et al. [28,29], Bonson [45], Ferri et. al. [39] and Kamble et al. [17] that perceived usability is the driving force behind blockchain technology adoption.

Practical implications and recommendations are as follows: this multi-case study research confirms that the biggest opportunity for blockchain adoption in SCF in supply chain processes is cost savings through increased efficiency, speed, innovation, standardization, automation and security; immutable distributed blockchain data creates trust, direct, digital and transparent; real time, trusted data, smart contracts via cryptography to drive automation practices for KYC and credit risk assessment issues; the process provides practical implications for efficient SCF practice; cost savings to automate processes and reduce the risk of illegal practices such as Trade-Based Money Laundering (TBML). Thus, it can be recommended for practitioners of SCF users to use blockchain technology, especially when involving various countries with diverse regulations that require trust, validity, speed and security.

Further research can be carried out relating to the relationship of financial institution partners to the successful implementation of the blockchain in SCF. Then, the research deals with open investment alternatives, especially with supply chain financing securitization. Although blockchain technology has great potential, there need to be examples of successful cases of application in supply chain finance. There needs to be a big step from financial institutions such as banks and trading offices to pioneer the use of blockchain technology. Then, it is also necessary to socialize the advantages of blockchain technology to the supply chain business community to enter the global supply chain ecosystem with new standards. So, the main obstacles to implementing blockchain technology in SCF are likely to be knowledge, willingness, trust and courage to take risks in the new supply chain ecosystems. Support from related parties in the supply chain, especially financial institutions and investors as funders, will encourage business opportunities and new types of investments.

Funding: This research received a research publication grant (No: 01-09-21-APC) from the Directorate of Research and Innovation, Universitas Prasetiya Mulya.

Acknowledgments: The author would like to thank the anonymous reviewers for providing suggestions and ways to improve scientific writing that have helped in improving this paper. The author is also grateful to the Research Center, Universitas Prasetiya Mulya, for their assistance in arranging the funding for the publication of this paper.

Conflicts of Interest: The author declares no conflict of interest.

\section{References}

1. Hofmann, E. Supply Chain Finance-Some Conceptual Insights. In Logistik Management; Springer: Berlin, Germany, 2005; pp. 203-214. [CrossRef]

2. Hofmann, E.; Belin, O. Supply Chain Finance Solutions; SpringerBriefs in Business; Springer: Berlin/Heidelberg, Germany, 2011; ISBN 978-3-642-17565-7.

3. Hofmann, E.; Zumsteg, S. Win-Win and No-Win Situations. In Supply Chain Finance: The Case of Accounts Receivable Programs; Taylor \& Francis: London, UK, 2016; Volume 16, pp. 30-50. [CrossRef]

4. Klapper, L. The Role of Factoring for Financing Small and Medium Enterprises. J. Bank. Financ. 2006, 30, 3111-3130. [CrossRef]

5. Klapper, L.F.; Laeven, L.; Rajan, R. Trade Credit Contracts; Oxford University Press: Oxford, UK, 2011.

6. Bryant, C.; Camerinelli, E. Supply Chain Finance European Market Guide Supply Chain Finance EBA European Market Guide; Euro Banking Association (EBA): Paris, France, 2013. Available online: https://www.abe-eba.eu/media/azure/production/1544/ebamarket-guide-on-supply-chain-finance-version-20.pdf (accessed on 11 June 2021). 
7. Gelsomino, L.M.; Mangiaracina, R.; Perego, A.; Tumino, A. Supply Chain Finance: A Literature Review. Int. J. Phys. Distrib. Logist. Manag. 2016, 46, 348-366. [CrossRef]

8. Pfohl, H.-C.; Gomm, M. Supply Chain Finance: Optimizing Financial Flows in Supply Chains. Logist. Res. 2009, 1, 149-161. [CrossRef]

9. Kouvelis, P.; Zhao, W. Supply Chain Contract Design under Financial Constraints and Bankruptcy Costs. Manag. Sci. 2016, 62, 2341-2357. [CrossRef]

10. Lekkakos, S.D.; Serrano, A. Supply Chain Finance for Small and Medium Sized Enterprises: The Case of Reverse Factoring. Int. J. Phys. Distrib. Amp Logist. Manag. 2016, 46, 367-392. [CrossRef]

11. Carter, C.R.; Rogers, D.S.; Choi, T.Y. Toward the Theory of the Supply Chain. J. Supply Chain Manag. 2015, 51, 89-97. [CrossRef]

12. Swan, M. Cryptocitizen: Smart Contracts, Pluralistic Morality, and Blockchain Society. 2015. Available online: https://e-learningteleformacion.blogspot.com/2016/12/cryptocitizen-smart-contracts.html (accessed on 5 March 2021).

13. Angelis, J.; Ribeiro da Silva, E. Blockchain Adoption: A Value Driver Perspective. Bus. Horiz. 2019, 62, 307-314. [CrossRef]

14. Kim, H.M.; Laskowski, M. Toward an Ontology-Driven Blockchain Design for Supply-Chain Provenance. Intell. Syst. Account. Financ. Manag. 2018, 25, 18-27. [CrossRef]

15. Crosby, M.; Pattanayak, P.; Verma, S.; Kalyanaraman, V. BlockChain Technology: Beyond Bitcoin. Applied Innovation Review; Sutardja Center for Entrepreneurship \& Technology, Berkeley Engineering: Berkeley, CA, USA, 2016; pp. 6-10. Available online: https:/ / www.appliedinnovationinstitute.org/blockchain-technology-beyond-bitcoin/ (accessed on 10 June 2021).

16. Ganne, E. Can Blockchain Revolutionize International Trade? 2018th ed.; WTO Publications, World Trade Organization: Geneva, Switzerland, 2018; ISBN 978-92-870-4760-1. Available online: https://www.wto.org/english/res_e/publications_e/ blockchainrev18_e.htm (accessed on 1 July 2021).

17. Kamble, S.S.; Gunasekaran, A.; Sharma, R. Modeling the Blockchain Enabled Traceability in Agriculture Supply Chain. Int. J. Inf. Manag. 2020, 52, 101967. [CrossRef]

18. Queiroz, M.M.; Fosso Wamba, S. Blockchain Adoption Challenges in Supply Chain: An Empirical Investigation of the Main Drivers in India and the USA. Int. J. Inf. Manag. 2019, 46, 70-82. [CrossRef]

19. Xie, Z.; Dai, S.; Chen, H.-N.; Wang, X. Blockchain Challenges and Opportunities: A Survey. Int. Congr. Big Data 2018, 14, $352-375$.

20. Hofmann, E.; Strewe, U.M.; Bosia, N. Supply Chain Finance and Blockchain Technology; Springer International: Cham, Switzerland, 2018. [CrossRef]

21. Folkinshteyn, D.; Lennon, M. Braving Bitcoin: A Technology Acceptance Model (TAM) Analysis. J. Inf. Technol. Case Appl. Res. 2017, 18, 220-249. [CrossRef]

22. Venkatesh, V.; Davis, F.D. A Theoretical Extension of the Technology Acceptance Model: Four Longitudinal Field Studies. Manag. Sci. 2000, 46, 186-204. [CrossRef]

23. Strieborny, M. Kukenova, M., Investment in Relationship-Specific Assets: Does Finance Matter? Rev. Financ. 2016, 20, 1487-1515. [CrossRef]

24. Davis, F.D. Perceived Usefulness, Perceived Ease of Use, and User Acceptance of Information Technology. MIS Q. Manag. Inf. Syst. 1989, 13, 319-339. [CrossRef]

25. Ajzen, I. Understanding Attitudes and Predicting Social Behavior; Prentice-Hall: Englewood Cliffs, NJ, USA, 1980.

26. Ajzen, I.; Fishbein, M. A Bayesian Analysis of Attribution Processes. Psychol. Bull. 1975, 82, 261-277. [CrossRef]

27. Venkatesh, V.; Davis, F.D. A Model of the Antecedents of Perceived Ease of Use: Development and Test. Decis. Sci. 1996, 27, 451-481. [CrossRef]

28. Jain, G.; Singh, H.; Chaturvedi, K.R.; Rakesh, S. Blockchain in Logistics Industry: In Fizz Customer Trust or Not. J. Enterp. Inf. Manag. 2020, 33, 541-558. [CrossRef]

29. Singh, H.; Jain, G.; Munjal, A.; Rakesh, S. Blockchain Technology in Corporate Governance: Disrupting Chain Reaction or Not? Corp. Gov. Int. J. Bus. Soc. 2019, 20, 67-86. [CrossRef]

30. Venkatesh, V.; Morris, M.G.; Davis, G.B.; Davis, F.D. User Acceptance of Information Technology: Toward a Unified View. MIS Q. Manag. Inf. Syst. 2003, 27, 425-478. [CrossRef]

31. van Raaij, E.M.; Schepers, J.J.L. The Acceptance and Use of a Virtual Learning Environment in China. Comput. Educ. 2008, 50, 838-852. [CrossRef]

32. Kamble, S.S.; Gunasekaran, A.; Kumar, V.; Belhadi, A.; Foropon, C. A Machine Learning Based Approach for Predicting Blockchain Adoption in Supply Chain. Technol. Forecast. Soc. Chang. 2021, 163, 120465. [CrossRef]

33. Eisenhardt, K.M. Agency Theory: An Assessment and Review. Acad. Manag. Rev. 1989, 14, 57. [CrossRef]

34. Yin, R.K. The Case Study Crisis: Some Answers. Adm. Sci. Q. 1981, 26, 58. [CrossRef]

35. Yin, R.K. Designing Case Studies. In Case Study Research and Applications: Design and Methods; SAGE Publications: Thousand Oaks, CA, USA, 2017; Volume 5, p. 414.

36. Yin, R.K. Case Study Methodology. In Case Study Research Design and Methods, 3rd ed.; Sage: Thousand Oaks, CA, USA, 2003; Volume 19-39, pp. 96-106.

37. Seawright, J.; Gerring, J. Case Selection Techniques in Case Study Research: A Menu of Qualitative and Quantitative Options. Political Res. Q. 2008, 61, 294-308. [CrossRef]

38. Persistent Digital Banking Solution. Available online: https://www.persistent.com/industries/banking-financial-services-andinsurance/digital-banking/ (accessed on 26 September 2021). 
39. Ferri, L.; Spanò, R.; Ginesti, G.; Theodosopoulos, G. Ascertaining Auditors' Intentions to Use Blockchain Technology: Evidence from the Big 4 Accountancy Firms in Italy. Meditari Account. Res. 2020. [CrossRef]

40. Pandl, K.D.; Thiebes, S.; Schmidt-Kraepelin, M.; Sunyaev, A. On the Convergence of Artificial Intelligence and Distributed Ledger Technology: A Scoping Review and Future Research Agenda. IEEE Access 2020, 8, 57075-57095. [CrossRef]

41. Lahkani, M.J.; Wang, S.; Urbański, M.; Egorova, M. Sustainable B2B E-Commerce and Blockchain-Based Supply Chain Finance. Sustainability 2020, 12, 3968. [CrossRef]

42. Global Spending on Blockchain Solutions. 2024. Available online: https://www-statista-com.upm.remotlog.com/statistics/8004 26/worldwide-blockchain-solutions-spending/ (accessed on 26 September 2021).

43. Babich, V.; Hilary, G. OM Forum-Distributed Ledgers and Operations: What Operations Management Researchers Should Know About Blockchain Technology. MSOM 2020, 22, 223-240. [CrossRef]

44. Sternberg, H.S.; Hofmann, E.; Roeck, D. The Struggle Is Real: Insights from a Supply Chain Blockchain Case. J. Bus. Logist. 2021, 42, 71-87. [CrossRef]

45. Bonsón, E.; Bednárová, M. Blockchain and Its Implications for Accounting and Auditing. Meditari Account. Res. 2019, 27, 725-740. [CrossRef] 